\title{
Perceived problems with computer gaming and internet use among adolescents: measurement tool for non-clinical survey studies
}

\author{
Bjørn E Holstein*, Trine Pagh Pedersen, Pernille Bendtsen, Katrine Rich Madsen, Charlotte Riebeling Meilstrup,
} Line Nielsen and Mette Rasmussen

\begin{abstract}
Background: Existing instruments for measuring problematic computer and console gaming and internet use are often lengthy and often based on a pathological perspective. The objective was to develop and present a new and short non-clinical measurement tool for perceived problems related to computer use and gaming among adolescents and to study the association between screen time and perceived problems.

Methods: Cross-sectional school-survey of 11-, 13-, and 15-year old students in thirteen schools in the City of Aarhus, Denmark, participation rate 89\%, $\mathrm{n}=2100$. The main exposure was time spend on weekdays on computer- and console-gaming and internet use for communication and surfing. The outcome measures were three indexes on perceived problems related to computer and console gaming and internet use.

Results: The three new indexes showed high face validity and acceptable internal consistency. Most schoolchildren with high screen time did not experience problems related to computer use. Still, there was a strong and graded association between time use and perceived problems related to computer gaming, console gaming (only boys) and internet use, odds ratios ranging from 6.90 to 10.23 .

Conclusion: The three new measures of perceived problems related to computer and console gaming and internet use among adolescents are appropriate, reliable and valid for use in non-clinical surveys about young people's everyday life and behaviour. These new measures do not assess Internet Gaming Disorder as it is listed in the DSM and therefore has no parity with DSM criteria. We found an increasing risk of perceived problems with increasing time spent with gaming and internet use. Nevertheless, most schoolchildren who spent much time with gaming and internet use did not experience problems.
\end{abstract}

Keywords: Adolescents, Children, Computer gaming, Epidemiology, Internet use, School survey, Screen time

\section{Background}

Computer gaming and internet use for communication and surfing is an important part of adolescents' life [1]. Most adolescents in Europe and North America spend two or more hours daily on computer-games and two or more hours on surfing and chatting via the internet. Time use exceeding four hours per day is common (unpublished analyses of HBSC international data 2010) [2]. Studies of young people's everyday life therefore need to address this behaviour and to examine whether it causes

\footnotetext{
* Correspondence: bho@niph.dk

National Institute of Public Health, University of Southern Denmark, Øster Farimagsgade 5A, DK 1353 Copenhagen K, Denmark
}

problems. A range of scholars have raised concerns about the risk of becoming addicted to these behaviours [3-9]. Many studies focus on negative side effects or cooccurrence with mental health problems [7,8,10-12], addictive behaviours [10-19], poor memory [20], poor school performance [21], poor cognitive function [20,22], withdrawal from social life [23], and neural damages [24-26]. According to Lortie \& Guitton [27], there seems to be consensus on the existence of problematic behaviour but less consensus on whether or not it involved addiction. Most of the commonly applied questionnaires regarding internet addiction address core dimensions of addiction such as compulsive use, negative outcomes, and 
salience [27]. Insight into young people's own perception about problems related to computer gaming and internet use may inform health education efforts to reduce such problems.

There is a debate whether excessive use of computer gaming and internet use is a disorder, a manifestation of an underlying psychopathology, a common behaviour, or whether it rather reflects a media-based moral panic [28-30]. It is important to conceptually separate nonproblematic and problematic use of these media [19,29] and to distinguish engagement from pathology $[29,31]$. According to Ferguson et al. [29], a large part of the literature about computer gaming and internet use reflects a pathological conceptual model. This literature applies terms as addiction, dependency, disorder, and compulsiveness. Many studies apply measures, which are rooted in the DSM-V criteria for addiction and pathological gambling $[3,15,25,32-34]$ or the ICD-10 criteria for dependency [9]. Other scholars adhere to what Ferguson et al. [29] labels the alternative model rather than a pathological model. These papers often examine motivation to engage in computer gaming and internet use and positive aspects of gaming and computer use, e.g. pain distraction [35], enhanced self-esteem or ego-clarity [1], the formation of social relations [36,37], stimulation of social skills [1], adherence to a cultural tendency [38,39], accessing updated information [6] and simply the fact that many young people are highly engaged in computer use $[19,31,36]$. The notion of high computer engagement is common in these papers [31,38]. These papers are often more concerned with screen time than pathology [5,34,40-42] and often focus on health issues such as physical inactivity [40], sedentary lifestyle, overweight [40,42], and sleep deprivation [20,43-45]. Especially, video-gaming seem to be difficult to categorise [46,47]. Several studies consider gaming and internet use as a continuum from computer engagement to addiction [47-49].

Most of the applied measures on computer gaming and internet use focus on negative side effects such as mental health problems. Most of these measures are long - typically more than 15 items. They are usually developed for clinical research and include items about the DSM-IV, DSM-V and ICD-10 criteria for internet addiction or compulsive computer gaming or pathological gambling [9,15,32-34,50-54]. Most of these measures include criteria for 1) withdrawal, 2) loss of control and 3) conflicts. According to King et al. [55] and Widyanto et al. [34] many instruments lack items about whether the individual believes that his/her gaming behaviour is problematic, and whether significant others consider that their gaming behaviour is problematic. We suggest that adolescents may perceive problems related to computer gaming and internet use which are non-pathological. Being engaged in school surveys about health and everyday life in adolescence, we feel there is a need for a measure which is short and simple for use in non-clinical research. This paper presents such a non-clinical measurement focusing on perceived problems related to computer use and gaming. It includes items about the individual's and significant others' perception of the behaviour being problematic.

Many papers have addressed screen time and the relationship between screen-time and perceived problems $[31,48,55]$. There seems to be a moderate correlation between screen-time and perceived problems but it is not clear how little screen-time may be sufficient to result in problems and how large screen-time may be unproblematic. The objectives of this paper is therefore 1) to present a new and short measurement tool for non-clinical research about perceived problems related to computer gaming and internet use and 2) to examine the relationship between screen time and these perceived problems.

\section{Methods}

\section{Design and study population}

The Aarhus School Survey was conducted in the city of Aarhus, the second largest city in Denmark (314,000 inhabitants). The overall aim was to investigate health, health behaviour, social relations and well-being of school. The survey is related to the cross-national Health Behaviour in School-aged Children (HBSC) study [2,56]. The sampling included 13 schools, strategically chosen to get a sufficient variation in socio-economic and migration background. All schoolchildren in grade five, seven, and nine (11-, 13- and 15-year-olds) were invited to complete a special version of the internationally standardized HBSC questionnaire [56]. The participation rate was $99 \%$ of the schoolchildren present on the day of data collection corresponding to $89 \%$ of the schoolchildren enrolled in the participating classes, $\mathrm{n}=2.100$.

\section{Ethical issues}

In Denmark there is no formal agency for approval of population based surveys and the schools decide autonomously whether to participate in such surveys. In each participating school, the school board, headmaster and schoolchildren's council had approved the study and the school nurse had been informed. The school board is the parents' representatives and they provided approval on behalf of the parents. The survey was conducted under full confidentiality, informed consent, and voluntary participation. The participants returned their questionnaire in sealed envelopes in order to protect their anonymity. There is no indication of name, date of birth, or school name in the data file, i.e. the data-file is totally anonymous. 


\section{Measurements}

As most measures of problematic computer-, consoleand internet use, we relied on self-reports of perceived problems [38,57-60]. We developed a first version of the questionnaire inspired by several scholars $[34,55,60]$ who propose to focus on the student's own perception of problems related to computer use, whether the family expresses concern, and whether the student feels bad in case of restricted access to computers. We tested this first version of the questionnaire among 44 schoolchildren in two age-groups (11- and 14-year-olds) and learned about the schoolchildren' perceptions and experiences in focus group discussions immediately after they had answered the questionnaire. We identified three kinds of perceived problems: 1) whether the respondent perceived him/herself to be dependent on computer gaming and internet use; 2) whether the respondent felt in a bad mood if not able to use computer or access the internet; 3) whether the parents showed concerns about the adolescent's use of computer/internet. The pilot test also showed that the schoolchildren distinguished between computer gaming, console-gaming, and use of the internet for communication and surfing (not for home work). This is the reason for asking separate questions for these three behaviours, although computer gaming and console-gaming are functionally similar behaviours.

Table 1 shows the final items and response categories. In the analyses, each variable was dichotomized into "Strongly agree" + "Partly agree" (coded 1) versus the remaining categories including missing values (coded 0 ). We constructed separate summary indexes for computer gaming, console-gaming and internet communication and surfing, range 0 to 3 . We consider $0-1$ as low and $2-3$ as high problem score. We applied the HBSC items about the time use for computer- and console gaming and use of computer. Table 1 also shows the items and categorization of screen time. The distribution of screen time for gaming was so different for boys and girls that we decided to apply different cut-points for boys and girls.

Parents' occupational social class was measured by the items: "Does your father/mother have a job? If yes, please say in what place he/she works. Please write exactly what job he/she does there". The responses were coded in accordance with the HBSC coding recommendations which have many similarities with the Registrar General Social Class measure [61]. Each student was classified by the highest ranking parent into high (I-II), medium (III-IV) and low (V + economically inactive) family social class. We included 'unclassifiable social class as a fourth and separate category in order to avoid losing too many observations in the analyses. Several validation studies have shown that children of the age of 11 and above can provide reliable and valid information about their parents' occupation $[62,63]$ although often with a high proportion of unclassifiable data. Family structure was based on schoolchildren's reports on whom they lived with and categorised into 1) traditional family (two biological parents), 2) single parent family (one single biological parent) and 3) reconstructed family (one biological parent + one stepparent). Again, we kept missing as a separate category to avoid losing too many observations. Schoolchildren living in other family structures $(n=15)$ were left out of analyses. We used the schoolchildren's reports about own and parents' country of birth as a measure of migration status, categorised into children with Danish background, immigrants and descendants.

\section{Statistical analyses}

We used explorative factor analysis, Spearman correlation coefficients, and Cronbach's coefficient alpha to assess the internal consistency (reliability) of the three indexes. We tested for differential item functioning (DIF) and observed that the indexes on problems related to computer gaming and problems related to console gaming functioned differently among boys and girls and differently in the three age groups. The index on problems related to internet use had DIF in relation to gender but not age group. Therefore, we conducted all analyses separately for boys and girls and checked all analyses for interaction with age group.

Associations between time spent on computer/console-gaming and score on index for problems related to computer gaming and problems related to console gaming, were estimated by multivariate logistic regression analyses in SAS version 9.1. Same analytical approach was applied to study the association between time spend on computer for communication, surfing or doing homework and score on problems related to internet use. All regression analyses were run as multilevel models by PROC GLIMMIX to account for the design effect caused by the cluster sampling. All analyses were adjusted by grade, family occupational social class, migration status, and family structure.

\section{Results}

For the three items forming the summary index on problems related to computer gaming, Cronbach's coefficient alpha was 0.72 . For the three items in the index on problems related to console-gaming alpha was 0.83 and for the three items in the index on problems related to internet communication and surf alpha was 0.76 . Table 2 shows the inter-correlation between these variables. Correlations are moderate to high between items within the same index and low to moderate across the three indexes. The exploratory factor analysis with nfactors $=3$ and varimax rotation showed the following variance explained by the three factors: $1.90,1.59$, and 1.37 . The 
Table 1 Measurement of time use and perceived problems related to computer-gaming, console-gaming, and internet use

Item wording

following statements on computer gaming?

Statements
1. I think I spend way too much time playing
computer games
2. I get in bad mood when I cannot spend time
on computer games
3. My parents tell me, I spend way too much time
on computer gaming

How much do you agree or disagree in the following statements on use of the Internet for surfing and chatting (not for homework)?

4. I think I spend way too much time on internet communication and surfing

5. I get in bad mood when I cannot spend time on internet communication and surfing

6. My parents say, that I spend way too much time on internet communication and surfing

How much do you agree or disagree in the following statements on console-gaming (PlayStation, Xbox, GameCube etc)?
7. I think I spend way too much time on console-gaming

8. I get in bad mood when I cannot spend time on console-gaming

9. My parents tell me, I spend way too much time on console-gaming

\begin{abstract}
In your leisure time: about how many hours a day do you usually spend playing computer or console games (PlayStation, Xbox, GameCube etc.)?
\end{abstract}

Responses were given separately for weekdays and weekends; we only use data about weekdays

\section{Response keys}

1. Strongly agree

2. Partly agree

3. Neither/nor

4. Partly disagree

5. Strongly disagree

1. Strongly agree

2. Partly agree

3. Neither/nor

4. Partly disagree

5. Strongly disagree

1. Strongly agree

2. Partly agree

3. Neither/nor

4. Partly disagree

5. Strongly disagree

1. None at all ${ }^{*}$
2. About $1 / 2$ an hour a day,
3. About 1 hour a day
4. About 2 hours a day,
5. About 3 hours a day
6. About 4 hours a day
7. About 5 hours a day
8. About 6 hours a day,
9. About 7 hours or more a day
1. None at all
2. About $1 / 2$ an hour a day,
3. About 1 hour a day
4. About 2 hours a day,
5. About 3 hours a day
6. About 4 hours a day
7. About 5 hours a day
8. About 6 hours a day,
9. About 7 hours or more a day ${ }^{\bar{N}}$ Trichotomized for analytical purposes. Due to varying distributions by gender it was not possible to apply similar cut-points for girls and boys. To ensure
sufficient power in all strata the following cut-points were applied: Girls: level $1=0$ hours/day, level $2=1 / 2$ hour/day, level $3=1$ hour or more/day; Boys: level $1=0-1 / 2$ hours/day, level $2=1$ hour/day, level $3=2$ hours or more/day. We use the label 'high time use' for level 3 .

${ }^{* *}$ level $1=0-1 / 2$ hours/day, level $2=1$ hour/day, level 3 (high time use) $=2$ hours or more/day for both boys and girls.

three factors within the same index had factor loadings $>0.60$ with only one exception.

Table 3 presents time spent on computer and console gaming and internet communication and surf on weekdays. The proportion that used the computer or console for gaming three hours or more on weekdays was $31.5 \%$ among boys and $6.2 \%$ among girls $(\mathrm{p}<0.0001)$. For both girls and boys, using three hours or more on the computer or console for gaming was most prevalent among seven graders (girls: $\mathrm{p}=0.0001$, boys: $\mathrm{p}=0.0218$ ). Among both boys and girls $17 \%$ used three hours or more on the internet for communication and surf. The 
Table 2 Inter-correlation ${ }^{*}$ between the nine items ${ }^{* *}$

\begin{tabular}{|c|c|c|c|c|c|c|c|c|c|}
\hline Item & 1 & 2 & 3 & 4 & 5 & 6 & 7 & 8 & 9 \\
\hline 1. I think I spend way too much time playing computer games & 1.00 & 0.37 & 0.63 & 0.30 & 0.09 & 0.23 & 0.40 & 0.24 & 0.30 \\
\hline 2. I get in bad mood when I cannot spend time on computer games & & 1.00 & 0.47 & 0.16 & 0.40 & 0.25 & 0.26 & 0.49 & 0.31 \\
\hline 3. My parents tell me, I spend way too much time on computer gaming & & & 1.00 & 0.19 & 0.12 & 0.41 & 0.30 & 0.28 & 0.42 \\
\hline 4. I think I spend way too much time on internet communication and surfing & & & & 1.00 & 0.46 & 0.57 & 0.19 & 0.15 & 0.15 \\
\hline 5. I get in bad mood when I cannot spend time on internet communication and surfing & & & & & 1.00 & 0.52 & 0.09 & 0.32 & 0.17 \\
\hline 6. My parents say, that I spend way too much time on internet communication and surfing & & & & & & 1.00 & 0.16 & 0.24 & 0.29 \\
\hline 7. I think I spend way too much time on console-gaming & & & & & & & 1.00 & 0.57 & 0.68 \\
\hline 8. I get in bad mood when I cannot spend time on console-gaming & & & & & & & & 1.00 & 0.63 \\
\hline 9. My parents tell me, I spend way too much time on console-gaming & & & & & & & & & 1.00 \\
\hline
\end{tabular}

*Spearman correlation coefficients, all correlation coefficients are statistically significant, $\mathrm{p}<0.0001$.

**The inter-correlations between the three indexes were: computer gaming and console gaming index 0.33 , computer gaming and internet use 0.28 , and console gaming and internet use 0.19 .

proportion of both girls and boys who used three hours or more on the internet was increasing with increasing age $(\mathrm{p}<0.0001)$. Table 3 also presents the distribution of included covariates.

Table 4 displays the proportion of participants who reported problems on each item and the distribution of participants on the three summary indexes. A score of 2 or 3 on the problems related to computer gaming index was more prevalent among boys $(22 \%)$ than girls $(7.8 \%)$ $(\mathrm{p}<0.0001)$. Among boys, problems related to computer gaming was most prevalent in grade nine $(\mathrm{p}=0.0295)$, among girls in grade five $(\mathrm{p}=0.0342)$. Scoring 2 or 3 on the index on problems related to console-gaming was more prevalent among boys (7.7\%) compared to girls $(2.1 \%)(\mathrm{p}<0.0001)$. For both boys and girls the highest prevalence of problems related to console-gaming was observed among fifth grade schoolchildren (boys: $\mathrm{p}<0.0001$, girls: $\mathrm{p}<0.0001)$. A score of 2 or 3 on the index on problems related to use of the internet for communication and surf was observed among more girls (13.4\%) than boys $(10.0 \%)(p=0.0158)$. Among both boys and girls, problems related to use of the internet was most prevalent in grade nine (girls: $\mathrm{p}=0.0003$, boys: $\mathrm{p}=0.0140$ ).

Table 5 presents the association between screen time and perceived problems. OR for problems related to computer gaming increased with time spend on gaming. OR for problems related to computer gaming was 9.51 (95\% CI: 4.35-20.79) among girls and 6.90 (3.98-11.94) among boys with high screen time. We found no significant interactions with gender and age. Problems related to console-gaming increased by gaming time, $\mathrm{OR}=10.23$ (3.12-33.51) among boys with high time use. Despite the high odds ratios, even among schoolchildren with a high level of screen time only a minority reported high level of perceived problems i relation to gaming or internet use (Figure 1). Testing for gender and age interaction revealed a significant gender difference $(\mathrm{p}<0.05)$. For both boys and girls the OR for problems related to use of internet for communication and surf increased with increased time spend on internet communication, surf and homework. The OR for perceived problems was 8.89 (4.72-16.75) among girls and 9.44 (4.72-18.88) among boys with high time use. We found no significant interactions with gender and age.

\section{Discussion}

This study presents a simple and straightforward measure of perceived problems related to computer gaming, console-gaming, and internet use for communication and surfing among adolescents. Like most other measures it is based on self-reported problems. Unlike most other measures it does not a priori consider excessive computer use and gaming as a disorder [29]. It is short and therefore appropriate for use in general health surveys and studies of adolescents' everyday life and behaviour. The measure separates three kinds of computer use: computer gaming, console-gaming, and internet use for communication and surfing. The face validity of these items was high and the internal consistency acceptable. We also acknowledge the shortages of this new measure: It is not linked to the DSM-V criteria for addiction and pathological gambling or the ICD-10 criteria for dependency. Therefore, the measure is not sufficient to detect pathological gaming and computer use and probably not appropriate for clinical research. Some of the items function differently for boys and girls and we suggest separate analyses for boys and girls.

This study reveals clear gender differences in prevalence of perceived problems regarding computer, console, and internet use: Problems related to computer and console-gaming were most prevalent among boys where it occurred among every fifth and almost every tenth boy, respectively. This gender difference is in accordance with the studies by van Rooij et al. [40] and Desai et al. [10]. Casale \& Fioavanti [64] found an opposite gender difference. Problems related to internet communication 
Table 3 Distribution of included variables

\begin{tabular}{|c|c|c|c|c|c|c|c|c|}
\hline & \multicolumn{4}{|c|}{ Girls } & \multicolumn{4}{|c|}{ Boys } \\
\hline & $\begin{array}{l}\text { All girls } \\
n=1069\end{array}$ & $\begin{array}{l}5 \text { th grade } \\
\mathrm{n}=389\end{array}$ & $\begin{array}{l}\text { 7th grade } \\
\mathrm{n}=397\end{array}$ & $\begin{array}{l}\text { 9th grade } \\
\mathrm{n}=\mathbf{2 8 3}\end{array}$ & $\begin{array}{l}\text { All boys } \\
n=1031\end{array}$ & $\begin{array}{l}\text { 5th grade } \\
\mathrm{n}=366\end{array}$ & $\begin{array}{l}\text { 7th grade } \\
\mathrm{n}=378\end{array}$ & $\begin{array}{l}\text { 9th grade } \\
n=287\end{array}$ \\
\hline $\begin{array}{l}\text { Gaming on computer or console: } \\
\text { hours per weekday }\end{array}$ & $\%$ & $\%$ & $\%$ & $\%$ & $\%$ & $\%$ & $\%$ & $\%$ \\
\hline 0 hour & 38.5 & 20.1 & 38.3 & 64.0 & 8.2 & 4.1 & 9.0 & 12.2 \\
\hline $1 / 2$ hour & 26.9 & 37.8 & 23.4 & 16.6 & 15.1 & 17.2 & 14.6 & 13.2 \\
\hline 1 hour & 18.3 & 24.9 & 17.4 & 10.6 & 21.1 & 24.9 & 20.4 & 17.1 \\
\hline 2 hours & 8.2 & 10.0 & 9.8 & 3.5 & 21.5 & 23.5 & 21.2 & 19.5 \\
\hline $3+$ hours & 6.2 & 5.7 & 8.3 & 3.9 & 31.5 & 26.2 & 33.6 & 35.5 \\
\hline Missing & 2.0 & 1.5 & 2.8 & 1.4 & 2.6 & 4.1 & 1.3 & 2.4 \\
\hline \multicolumn{9}{|l|}{ Internet use: hours per weekday } \\
\hline 0 hour & 10.5 & 20.3 & 6.8 & 2.1 & 14.4 & 28.4 & 10.6 & 1.4 \\
\hline $1 / 2$ hour & 24.0 & 33.7 & 20.4 & 15.6 & 27.2 & 32.5 & 25.9 & 22.0 \\
\hline 1 hour & 26.4 & 27.0 & 24.4 & 28.3 & 22.1 & 18.0 & 25.7 & 22.7 \\
\hline 2 hours & 20.0 & 11.8 & 24.4 & 25.1 & 16.0 & 11.2 & 15.9 & 22.3 \\
\hline $3+$ hours & 17.0 & 5.4 & 20.7 & 27.9 & 17.8 & 6.6 & 20.6 & 28.6 \\
\hline Missing & 2.2 & 1.8 & 3.3 & 1.1 & 2.5 & 3.3 & 1.3 & 3.1 \\
\hline \multicolumn{9}{|l|}{ Family social class } \\
\hline High & 42.4 & 40.9 & 43.6 & 42.8 & 43.6 & 40.7 & 45.0 & 45.3 \\
\hline Middle & 27.6 & 23.7 & 29.2 & 30.7 & 25.6 & 24.6 & 24.6 & 28.2 \\
\hline Low & 16.2 & 16.2 & 15.4 & 17.3 & 12.7 & 11.2 & 13.8 & 13.2 \\
\hline Non-classifiable & 12.3 & 18.0 & 10.1 & 7.4 & 16.1 & 21.9 & 13.8 & 11.9 \\
\hline Missing & 1.6 & 1.3 & 1.8 & 1.8 & 2.0 & 1.6 & 2.9 & 1.4 \\
\hline \multicolumn{9}{|l|}{ Migration status } \\
\hline Natives & 82.0 & 84.1 & 82.1 & 78.8 & 83.2 & 83.6 & 83.3 & 82.6 \\
\hline Migrants & 5.1 & 4.1 & 6.1 & 5.0 & 5.3 & 4.6 & 4.8 & 7.0 \\
\hline Descendants & 12.4 & 11.6 & 10.8 & 15.6 & 10.1 & 9.8 & 10.9 & 9.4 \\
\hline Missing & 0.7 & 0.3 & 1.0 & 0.7 & 1.4 & 1.9 & 1.1 & 1.1 \\
\hline \multicolumn{9}{|l|}{ Family structure } \\
\hline Traditional & 53.8 & 53.2 & 53.9 & 54.4 & 56.7 & 60.7 & 53.7 & 55.8 \\
\hline Single & 20.2 & 19.3 & 21.9 & 19.1 & 20.0 & 16.9 & 20.1 & 23.7 \\
\hline Reconstructed & 10.4 & 8.0 & 10.3 & 13.8 & 7.8 & 5.7 & 7.9 & 10.1 \\
\hline Other & 0.9 & 1.0 & 0.8 & 1.2 & 0.5 & 0.6 & 0.3 & 0.7 \\
\hline Missing & 14.7 & 18.5 & 13.1 & 11.7 & 15.0 & 16.1 & 18.0 & 9.8 \\
\hline
\end{tabular}

and surfing was most prevalent among girls where it was experienced by around $13 \%$.

The prevalence of perceived problems showed interesting patterns across age. The youngest age groups seem to be most burdened by problems related to console-gaming and among girls also problems related to computer gaming. Among boys problems related to computer use was most prevalent among the older schoolchildren. These findings suggest that the three different kinds of screen and computer time may appeal differently to boys and girls in different age groups. Bonetti et al. [23] also finds that girls use more time online communicating with friends. The prevalence of perceived problems related to computer and consolegaming, and internet use for communication and surf increased with increasing screen time. Perceived problems occurred even among adolescents with a relatively low time use for gaming and internet use. Other studies on mental health side effects of gaming and internet use typically show problems among adolescents who use extremely many hours in front of their computer, e.g. more than five hours per day [54]. The available studies do agree that there is no linear and strong correlation between time use and problems related to gaming and 
Table 4 Prevalence of perceived problems and the participants' distribution on the three indexes

\begin{tabular}{|c|c|c|c|c|c|c|c|c|}
\hline & \multicolumn{4}{|c|}{ Girls } & \multicolumn{4}{|c|}{ Boys } \\
\hline & $\begin{array}{l}\text { All girls } \\
\mathrm{n}=1069\end{array}$ & $\begin{array}{l}\text { 5th grade } \\
\mathrm{n}=389\end{array}$ & $\begin{array}{l}\text { 7th grade } \\
\mathrm{n}=397\end{array}$ & $\begin{array}{l}\text { 9th grade } \\
\mathrm{n}=\mathbf{2 8 3}\end{array}$ & $\begin{array}{l}\text { All boys } \\
\mathrm{n}=1031\end{array}$ & $\begin{array}{l}\text { 5th grade } \\
\mathrm{n}=366\end{array}$ & $\begin{array}{l}\text { 7th grade } \\
\mathrm{n}=378\end{array}$ & $\begin{array}{l}\text { 9th grade } \\
\mathrm{n}=287\end{array}$ \\
\hline Computer gaming, \% strongly + partly agree: & $\%$ & $\%$ & $\%$ & $\%$ & $\%$ & $\%$ & $\%$ & $\%$ \\
\hline $\begin{array}{l}\text { I think I spend way too much time playing } \\
\text { computer games }\end{array}$ & 13.5 & 19.8 & 12.6 & 6.0 & 25.9 & 24.6 & 24.9 & 28.9 \\
\hline $\begin{array}{l}\text { I get in bad mood when I cannot spend time on } \\
\text { computer games }\end{array}$ & 5.6 & 6.7 & 5.3 & 4.6 & 11.4 & 11.5 & 10.8 & 12.2 \\
\hline $\begin{array}{l}\text { My parents tell me, I spend way too much time on } \\
\text { computer gaming }\end{array}$ & 11.3 & 14.9 & 11.6 & 6.0 & 32.2 & 26.5 & 34.1 & 36.9 \\
\hline \multicolumn{9}{|l|}{ Index for problems related to computer gaming } \\
\hline 0 & 79.1 & 71.2 & 79.9 & 88.7 & 56.4 & 59.3 & 55.8 & 53.3 \\
\hline 1 & 13.2 & 18.8 & 12.3 & 6.7 & 21.6 & 22.1 & 22.8 & 19.5 \\
\hline 2 & 6.1 & 7.5 & 6.3 & 3.9 & 18.1 & 15.3 & 17.2 & 23.0 \\
\hline 3 & 1.7 & 2.6 & 1.5 & 0.7 & 3.9 & 3.3 & 4.2 & 4.2 \\
\hline \multicolumn{9}{|l|}{ Console-gaming, \% strongly + partly agree: } \\
\hline I think I spend way too much time on console-gaming & 3.7 & 6.9 & 2.3 & 1.4 & 10.0 & 11.2 & 9.8 & 8.7 \\
\hline $\begin{array}{l}\text { I get in bad mood when I cannot spend time } \\
\text { on console-gaming }\end{array}$ & 2.4 & 3.3 & 2.0 & 1.8 & 6.5 & 7.4 & 5.0 & 7.3 \\
\hline $\begin{array}{l}\text { My parents tell me, I spend way too much time on } \\
\text { console-gaming }\end{array}$ & 2.7 & 4.9 & 1.8 & 3.9 & 11.4 & 12.8 & 10.9 & 10.1 \\
\hline \multicolumn{9}{|l|}{ Index for problems related to console-gaming } \\
\hline 0 & 94.4 & 90.5 & 96.0 & 97.5 & 82.3 & 80.9 & 82.3 & 84.0 \\
\hline 1 & 3.5 & 5.9 & 2.5 & 1.4 & 10.0 & 9.8 & 11.4 & 8.4 \\
\hline 2 & 1.0 & 1.5 & 1.0 & 0.4 & 5.4 & 6.3 & 4.8 & 5.2 \\
\hline 3 & 1.1 & 2.1 & 0.5 & 0.7 & 2.3 & 3.0 & 1.6 & 2.4 \\
\hline \multicolumn{9}{|l|}{ Internet use, \% strongly + partly agree: } \\
\hline $\begin{array}{l}\text { I think I spend way too much time on internet } \\
\text { communication and surfing }\end{array}$ & 18.2 & 11.8 & 20.4 & 24.0 & 13.2 & 12.6 & 11.9 & 15.7 \\
\hline $\begin{array}{l}\text { I get in bad mood when I cannot spend time on } \\
\text { internet communication and surfing }\end{array}$ & 13.8 & 7.2 & 16.4 & 19.1 & 8.3 & 4.9 & 9.3 & 11.5 \\
\hline $\begin{array}{l}\text { My parents tell me, that I spend way too much } \\
\text { time on internet communication and surfing }\end{array}$ & 15.3 & 8.2 & 19.4 & 19.4 & 14.4 & 11.2 & 13.8 & 19.2 \\
\hline \multicolumn{9}{|l|}{ Index for problems related to Internet use } \\
\hline 0 & 70.1 & 82.5 & 64.7 & 60.4 & 76.3 & 81.2 & 76.5 & 70.0 \\
\hline 1 & 16.6 & 9.5 & 19.7 & 21.9 & 13.7 & 11.2 & 14.6 & 15.7 \\
\hline 2 & 9.4 & 6.2 & 10.3 & 12.4 & 7.8 & 5.5 & 6.6 & 12.2 \\
\hline 3 & 4.0 & 1.8 & 5.3 & 5.3 & 2.2 & 2.2 & 2.4 & 2.1 \\
\hline
\end{tabular}

computer use $[31,40,48,54,55,65]$. Our study also shows that even among participants who use more than three hours per day in front of their computer or console, the majority do not perceive problems.

Because of the cross-sectional design we cannot draw causal conclusions about the association between screen time and problems related to computer gaming and internet use. The participation rate was high and we do not anticipate substantial selection bias. If the $11 \%$ nonparticipants include a substantial proportion of schoolchildren with excessive screen time and high prevalence of perceived problems, then the study may have under- estimated the association between screen time and perceived problems.

The data collection reflects the year of data collection in which smartphones and tablet computers were rare. The applied HBSC measurement of time use does not completely reflect the measures of perceived problems because the measure of computer time use also includes time spend at the computer doing homework. Also, the measure of time spend on gaming both involve computer and console-gaming while problems related to computer gaming and problems related to console-gaming are measured by two distinct indexes. This information bias 
Table 5 OR $(95 \% \mathrm{Cl})$ for perceived problems related to computer gaming, console-gaming, and internet use by time spend on computer/console-gaming and computer use for communication and surf

\begin{tabular}{|c|c|c|}
\hline \multirow[b]{2}{*}{ Time spend on weekdays on computer or console gaming ${ }^{b}$} & \multicolumn{2}{|c|}{ OR for problems related to computer gaming ${ }^{\mathrm{a}}$} \\
\hline & Girls & Boys \\
\hline & $n=1016$ & $n=967$ \\
\hline Level 1 (lowest) & 1.0 & 1.0 \\
\hline Level 2 & $2.45(0.99-6.01)$ & $1.74(0.89-3.39)$ \\
\hline \multirow[t]{2}{*}{ Level 3} & $9.51(4.35-20.79)$ & $6.90(3.98-11.94)$ \\
\hline & \multicolumn{2}{|c|}{ OR for problems related to console gaming ${ }^{a}$} \\
\hline \multirow[t]{2}{*}{ Time spend on weekdays on computer or console gaming ${ }^{b}$} & Girls & Boys \\
\hline & $n=1016$ & $n=967$ \\
\hline Level 1 (lowest) & 1.0 & 1.0 \\
\hline Level 2 & $1.49(0.44-4.99)$ & $4.61(1.27-16.81)$ \\
\hline \multirow[t]{2}{*}{ Level 3} & $1.37(0.43-4.42)$ & $10.23(3.12-33.51)$ \\
\hline & \multicolumn{2}{|c|}{ OR for problems related to computer communication and surfa } \\
\hline \multirow[t]{2}{*}{ Time spend on weekdays on computer communication and surf ${ }^{c}$} & Girls & Boys \\
\hline & $n=1014$ & $n=968$ \\
\hline Level 1 (lowest) & 1.0 & 1.0 \\
\hline Level 2 & $2.15(1.04-4.41)$ & $2.03(0.86-4.79)$ \\
\hline Level 3 & $8.89(4.72-16.75)$ & $9.44(4.72-18.88)$ \\
\hline
\end{tabular}

*Analyses stratified by gender and adjusted by age group, family social class, migration status, and family structure.

a Perceived problems related to computer/console-gaming and problems related to computer communication and surf is defined by scores of 2 or 3 on the summary indexes.

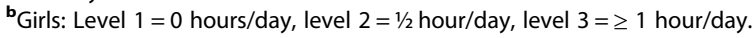

Boys: Level $1=0-1 / 2$ hour $/$ day, level $2=1$ hour/day, level $3=\geq 2$ hours $/$ day.

'Level $1=0-1 / 2$ hour/day, level $2=1$ hour/day, level $3=\geq 2$ hours/day.

complicates the interpretation of the findings. Still, we think that the association between screen time and perceived problems is convincing. Another information bias that may complicate interpretation is the different cut-points for screen time among boys and girls. Unfortunately, the distribution of the screen time variable differed so much that it called for different cut-points among boys and girls. The measure of screen time is not comparable across gender on an absolute scale.
The study focuses on time use for computer and console gaming use and not the kind of gaming. The perception of problems related to gaming and internet use may differ by the content, i.e. that violent games and role-playing games may have different consequences [5]. Finally, unmeasured confounding may exist. Factors such as parental guidance and parental monitoring [9], psycho-pathology [66], and personality [16] may be potential confounders. Unfortunately, such data were not available in our study. We also

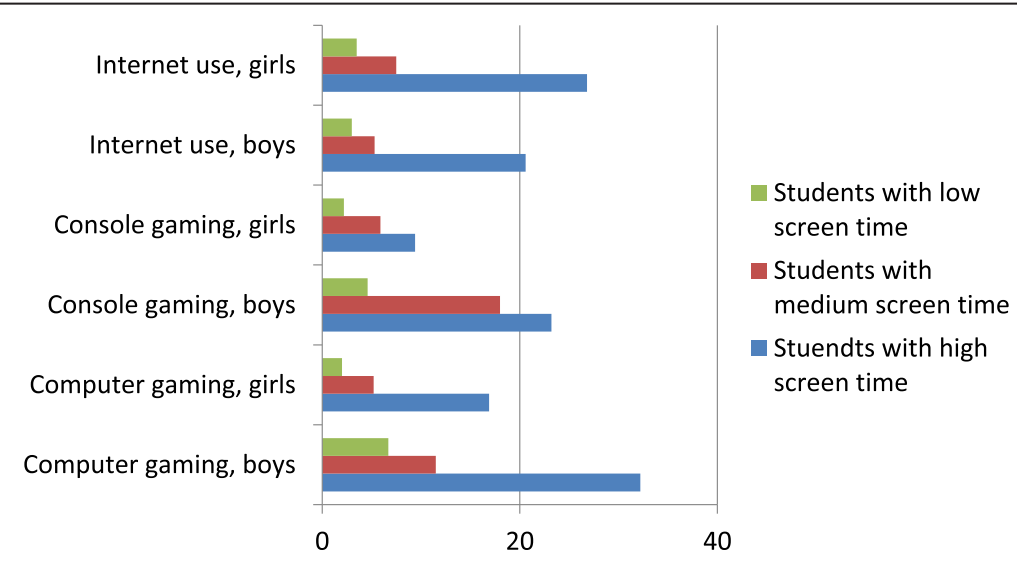

Figure 1 Prevalence (\%) of perceived problems related to computer-gaming, console-gaming, and internet use by screen time. 
missed data about the motivation to spend time for gaming and computer use.

We think there is a need for a brief and non-pathological measure, which we present in this paper. We propose to use this new measure to study how gaming and computer use behaviour is associated with other aspects of young people's daily life $[67,68]$, e.g. family structure, social relations, and health behaviours. It is important to test the validity, internal consistency and applicability in other study populations and other settings. We propose studies, which check the association between this new measure and potential side effects of gaming and internet use. We also suggest studies of why some young people perceive many problems in relation to computer gaming and internet use. Studies based on qualitative interviews may be appropriate to address this issue. It is important to identify groups of young people who are susceptible to problems if they spend much time by the computer or console screen and to develop appropriate ways to deal with the perceived problems. Finally, we need to know why some young people apparently spend excessive numbers of hours on gaming and internet use without experiencing any of the above problems.

\section{Conclusion}

The three new measures of perceived problems related to computer and console gaming and internet use among adolescents are appropriate, reliable and valid for use in non-clinical surveys about young people's everyday life and behaviour. These new measures do not assess Internet Gaming Disorder as it is listed in the DSM and therefore has no parity with DSM criteria. We found an increasing risk of perceived problems with increasing time spent with gaming and internet use. Nevertheless, most schoolchildren who spent much time with gaming and internet use did not experience problems.

\section{Competing interests}

The authors declare that they have no competing interests.

\section{Authors' contributions}

MR, KRM, TPP and BEH planned the entire study and were responsible for the data collection. All authors (PB, BEH, KRM, CRM, LN, TPP and MR) were involved in planning the paper and the statistical analyses. MR performed the analyses, TPP drafted the Results section. MR and BEH drafted the introduction, the Methods section and the Discussion. All authors (PB, BEH, KRM, CRM, LN, TPP and MR) contributed to the final revision of the manuscript. All authors read and approved the final manuscript.

\section{Acknowledgements}

We thank Poul Lundsgaard Bak, Henriette Hansen, Sheila Terp, and Anette $\varnothing$ stergaard from the City of Aarhus for their important contribution to the planning of the study and data collection. We thank the Nordea Foundation and the The Danish Council for Independent Research (09-065450) for financial support to the study.

Received: 9 November 2012 Accepted: 7 April 2014 Published: 15 April 2014

\section{References}

1. Valkenburg PM, Peter J: Online communication among adolescents: an integrated model of its attraction, opportunities, and risks. J Adolesc Health 2011, 48:121-127.

2. Currie C, Zanotti C, Morgan A, Currie D, de Looze M, Roberts C, Samdal O, Smith ORF, Barnekow: Social determinants of health and well-being among young people. Health Behaviour in School-aged Children (HBSC) study. Copenhagen: World Health Organization; 2012.

3. Aboujaoude E: Problematic Internet use: an overview. World Psychiatry 2010, 9:85-90.

4. Flisher C: Getting plugged in: an overview of internet addiction. J Paediatr Child Health 2010, 46:557-559.

5. Holtz $\mathrm{P}$, Appel M: Internet use and video gaming predict problem behavior in early adolescence. J Adolesc 2011, 34:49-58.

6. Israelashvili M, Kim T, Bukobza G: Adolescents' over-use of the cyber world-Internet addiction or identity exploration? J Adolesc 2012, 35:417-424.

7. Moreno MA, Jelenchick L, Cox E, Young H, Christakis DA: Problematic internet use among US youth: a systematic review. Arch Pediatr Adolesc Med 2011, 165:797-805.

8. Morrison $\mathrm{CM}$, Gore $\mathrm{H}$ : The relationship between excessive Internet use and depression: a questionnaire-based study of 1,319 young people and adults. Psychopathology 2010, 43:121-126.

9. Walther B, Morgenstern M, Hanewinkel R: Co-occurrence of addictive behaviours: personality factors related to substance use, gambling and computer gaming. Eur Addict Res 2012, 18:167-174.

10. Desai RA, Krishnan-Sarin S, Cavallo D, Potenza MN: Video-gaming among high school students: health correlates, gender differences, and problematic gaming. Pediatrics 2010, 126:e1414-e1424.

11. Liu TC, Desai RA, Krishnan-Sarin S, Cavallo DA, Potenza MN: Problematic Internet use and health in adolescents: data from a high school survey in Connecticut. J Clin Psychiatry 2011, 72:836-845.

12. Lorains FK, Cowlishaw S, Thomas SA: Prevalence of comorbid disorders in problem and pathological gambling: systematic review and meta-analysis of population surveys. Addiction 2011, 106:490-498.

13. Fisoun V, Floros $G$, Siomos $K$, Geroukalis $D$, Navridis K: Internet addiction as an important predictor in early detection of adolescent drug use experience-implications for research and practice. J Addict Med 2012, 6:77-84.

14. Grusser SM, Thalemann R, Griffiths MD: Excessive computer game playing: evidence for addiction and aggression? Cyberpsychol Behav 2007, 10:290-292.

15. Ko CH, Yen JY, Yen CF, Chen CC, Yen CN, Chen SH: Screening for Internet addiction: an empirical study on cut-off points for the Chen Internet Addiction Scale. Kaohsiung J Med Sci 2005, 21:545-551.

16. Slutske W, Caspi A, Moffitt T, Poulton R: Personality and problem gambling. A prospective study of birth cohort of young adults. Arch Gen Psychiatry 2005, 62:769-775.

17. Spritzer DT, Rohde LA, Benzano DB, Laranjeira RR, Pinsky I, Zaleski M, Caetano R, Tavares H: Prevalence and correlates of gambling problems among a nationally representative sample of Brazilian adolescents. J Gambl Stud 2011, 27:649-661.

18. Sun $P$, Johnson CA, Palmer $P$, Arpawong TE, Unger JB, Xie B, Rohrbach LA, Spruit-Metz D, Sussman S: Concurrent and predictive relationships between compulsive internet use and substance use: findings from vocational high school students in China and the USA. Int J Environ Res Public Health 2012, 9:660-673.

19. Weinstein A, Lejoyeux M: Internet addiction or excessive internet use. Am J Drug Alcohol Abuse 2010, 36:277-283.

20. Dworak M, Schierl T, Bruns T, Struder HK: Impact of singular excessive computer game and television exposure on sleep patterns and memory performance of school-aged children. Pediatrics 2007, 120:978-985.

21. Skoric MM, Teo LL, Neo RL: Children and video games: addiction, engagement, and scholastic achievement. Cyberpsychol Behav 2009, 12:567-572.

22. Park MH, Park EJ, Choi J, Chai S, Lee JH, Lee C, Kim DJ: Preliminary study of Internet addiction and cognitive function in adolescents based on IQ tests. Psychiatry Res 2011, 190:275-281.

23. Bonetti L, Campbell MA, Gilmore L: The relationship of loneliness and social anxiety with children's and adolescents' online communication. Cyberpsychol Behav Soc Netw 2010, 13:279-285. 
24. Balodis IM, Lacadie CM, Potenza MN: A Preliminary Study of the Neural Correlates of the Intensities of Self-Reported Gambling Urges and Emotions in Men with Pathological Gambling. J Gamb/ Stud 2012, 283:493-513.

25. van Holst RJ, Lemmens JS, Valkenburg PM, Peter J, Veltman DJ, Goudriaan AE: Attentional bias and disinhibition toward gaming cues are related to problem gaming in male adolescents. J Adolesc Health 2012, 50:541-546.

26. Yuan K, Qin W, Wang G, Zeng F, Zhao L, Yang X, Liu P, Liu J, Sun J, von Deneen KM, Gong Q, Liu Y, Tian J: Microstructure abnormalities in adolescents with internet addiction disorder. PLoS One 2011, 6:e20708.

27. Lortie $\mathrm{CL}$, Guitton MJ: Internet addiction assessment tools: dimensional structure and methodological status. Addiction 2013, 108:1207-1216.

28. Dowling N, Smith D, Thomas T: Electronic gaming machines: are they the 'crack-cocaine' of gambling? Addiction 2005, 100:33-45.

29. Ferguson CJ, Coulson M, Barnett J: A meta-analysis of pathological gaming prevalence and comorbidity with mental health, academic and social problems. J Psychiatr Res 2011, 45:1573-1578.

30. Starcevic V: Problematic Internet use: a distinct disorder, a manifestation of an underlying psychopathology, or a troublesome behaviour? World Psychiatry 2010, 9:92-93.

31. Charlton JP, Danforth IDW: Distinguishing addiction and high engagement in the context of online game playing. Comput Hum Behav 2007, 23:1531-1548.

32. Demetrovics Z, Szeredi B, Rozsa S: The three-factor model of Internet addiction: the development of the Problematic Internet Use Questionnaire. Behav Res Methods 2008, 40:563-574

33. Jelenchick $L A$, Becker $T$, Moreno MA: Assessing the psychometric properties of the Internet Addiction Test (IAT) in US college students. Psychiatry Res 2012, 196:296-301.

34. Widyanto L, Griffiths MD, Brunsden V: A psychometric comparison of the Internet Addiction Test, the Internet-Related Problem Scale, and self-diagnosis. Cyberpsychol Behav Soc Netw 2011, 14:141-149.

35. Jameson E, Trevena J, Swain N: Electronic gaming as pain distraction. Pain Res Manag 2011, 16:27-32.

36. Durkin K, Barber B: Not so doomed: computer game play and positive adolescent development. Applied Developmental Psychology 2002, 23:373-392

37. Valkenburg P, Peter J: The effects of instant messaging on the quality of adolescents' existing friendships: a longitudinal study. J Communication 2009, 59:79-97.

38. Charlton JP: A factor-analytic investigation of computer 'addiction' and engagement. Br J Psychol 2002, 93:329-344

39. Leung L: Net-generation attributes and seductive properties of the internet as predictors of online activities and internet addiction. Cyberpsychol Behav 2004, 7:333-348.

40. van Rooij AJ, Schoenmakers TM, van de Eijnden RJ, van de Mheen D: Compulsive Internet use: the role of online gaming and other internet applications. J Adolesc Health 2010, 47:51-57.

41. Salmon J, Timperio A, Telford A, Carver A, Crawford D: Association of family environment with children's television viewing and with low level of physical activity. Obesity Res 2005, 13:1939-1951.

42. Graves LE, Ridgers ND, Atkinson G, Stratton G: The effect of active video gaming on children's physical activity, behavior preferences and body composition. Pediatr Exerc Sci 2010, 22:535-546.

43. Li S, Zhu S, Jin X, Yan C, Wu S, Jiang F, Shen X: Risk factors associated with short sleep duration among Chinese school-aged children. Sleep Med 2010, 11:907-916.

44. Owens LJ, France KG, Wiggs L: REVIEW ARTICLE: Behavioural and cognitive-behavioural interventions for sleep disorders in infants and children: A review. Sleep Med Rev 1999, 3:281-302

45. Siomos KE, Braimiotis D, Floros GD, Dafoulis V, Angelopoulos NV: Insomnia symptoms among Greek adolescent students with excessive computer use. Hippokratia 2010, 14:203-207.

46. King DL, Delfabbro PH: Issues for DSM-5: Video-gaming disorder? Aust N Z J of Psychiatry 2012, 47:20-22. viewpoint.

47. Porter $G$, Starcevic $V$, Berle D, Fenech P: Recognizing problem video game use. Aust N Z J Psychiatry 2010, 44:120-128.

48. Gentile DA, Choo H, Liau A, Sim T, Li D, Fung D, Khoo A: Pathological video game use among youths: a two-year longitudinal study. Pediatrics 2011, 127:e319-e329.
49. Tao R, Huang X, Wang J, Zhang Y, Li M: Proposed diagnostic criteria for internet addiction. Addiction 2010, 105:556-564

50. Cao H, Sun Y, Wan Y, Hao J, Tao F: Problematic Internet use in Chinese adolescents and its relation to psychosomatic symptoms and life satisfaction. BMC Public Health 2011, 11:802.

51. Davis RA, Flett GL, Besser A: Validation of a new scale for measuring problematic internet use: implications for pre-employment screening. Cyberpsychol Behav 2002, 5:331-345.

52. Lemmens JS, Valkenburg PM, Peter J: Development and validation of a game addiction scale for adolescents. Media Psychology 2009, 12:77-95.

53. Rehbein F, Kleimann M, Mossle T: Prevalence and Risk Factors of Video Game Dependency in Adolescence: Results of a German Nationwide Survey. Cyberpsychol Behav 2010, 13:269-277.

54. Young K, Rogers R: The relationsship between depression and internet addiction. Cyberpsychol Behav 1998, 1:25-28.

55. King DL, Haagsma MC, Delfabbro PH, Gradisar M, Griffiths MD: Toward a consensus definition of pathological video-gaming: A systematic review of psychometric assessment tools. Clin Psychol Rev 2013, 33:331-342.

56. Roberts C, Freeman J, Samdal O, Schnohr CW, de Looze ME, Nic Gabhainn S, lannotti R, Rasmussen M: The Health Behaviour in School-aged Children (HBSC) study: methodological developments and current tensions. Int J Public Health 2009, 54(Suppl 2):140-150

57. Beard KW: Internet addiction: a review of current assessment techniques and potential assessment questions. Cyberpsychol Behav 2005, 8:7-14.

58. Ellenbogen S, Gupta R, Derevensky JL: A cross-cultural study of gambling behaviour among adolescents. J Gamb/ Stud 2007, 23:25-39.

59. Ellenbogen S, Derevensky J, Gupta R: Gender differences among adolescents with gambling-related problems. J Gamb/ Stud 2007, 23:133-143.

60. Salguero R, Morán R: Measuring problem video game playing in adolescents. Addiction 2002, 97:1601-1606.

61. Macintyre S, McKay L, Der G, Hiscock R: Socio-economic position and health: what you observe depends on how you measure it. J Public Health Med 2003, 25:288-294.

62. Lien N, Friestad C, Klepp Kl: Adolescents' proxy reports of parents' socioeconomic status: How valid are they? J Epidemiol Community Health 2001, 55:731-737.

63. Vereecken C, Vandegehuchte A: Measurement of parental occupation: Agreement between parents and their children. Arch Public Health 2003, 61:141-149.

64. Casale S, Fioravanti G: Psychosocial correlates of internet use among Italian students. Int J Psychol 2011, 46:288-298.

65. Young K, Pistner M, O'Mara J, Buchanan J: Cyber disorders: the mental health concern for the new millennium. Cyberpsychol Behav 1999, 2:475-479.

66. Ko CH, Yen JY, Chen CS, Yeh YC, Yen CF: Predictive values of psychiatric symptoms for internet addiction in adolescents: a 2-year prospective study. Arch Pediatr Adolesc Med 2009, 163:937-943.

67. Kormas G, Critselis E, Janikian M, Kafetzis D, Tsitsika A: Risk factors and psychosocial characteristics of potential problematic and problematic internet use among adolescents: a cross-sectional study. BMC Public Health 2011, 11:595.

68. Milani L, Osualdella D, Di BP: Quality of interpersonal relationships and problematic Internet use in adolescence. Cyberpsychol Behav 2009, 12:681-684.

doi:10.1186/1471-2458-14-361

Cite this article as: Holstein et al:: Perceived problems with computer gaming and internet use among adolescents: measurement tool for non-clinical survey studies. BMC Public Health 2014 14:361. 